\title{
Article \\ Revisiting Small- and Medium-Sized Enterprises' Innovation and Resilience during COVID-19: The Tourism Sector
}

\author{
Álvaro Lopes Dias ${ }^{1,2, * \mathbb{C}}$, Inês Cunha ${ }^{2}$, Leandro Pereira ${ }^{3}$, Renato Lopes Costa ${ }^{3}$ and Rui Gonçalves ${ }^{4}$ (D) \\ 1 TRIE, Universidade Lusófona, 1749-024 Lisbon, Portugal \\ 2 DMOGG, ISCTE-IUL, 1649-026 Lisbon, Portugal; inestcunha@sapo.pt \\ 3 Business Research Unit, Lisbon University Institute, 1649-026 Lisbon, Portugal; \\ leandro.pereira@winning.pt (L.P.); renato.costa@businesscaseinstitute.org (R.L.C.) \\ 4 Instituto Piaget, 2805-059 Almada, Portugal; ruiahgoncalves@gmail.com \\ * Correspondence: alvaro.dias1@gmail.com
}

check for updates

Citation: Dias, Á.L.; Cunha, I.; Pereira, L.; Costa, R.L.; Gonçalves, R. Revisiting Small- and Medium-Sized Enterprises' Innovation and Resilience during COVID-19: The Tourism Sector. J. Open Innov. Technol. Mark. Complex. 2022, 8, 11. https:// doi.org/10.3390/joitmc8010011

Received: 17 November 2021 Accepted: 26 December 2021 Published: 6 January 2022

Publisher's Note: MDPI stays neutral with regard to jurisdictional claims in published maps and institutional affiliations.

Copyright: () 2022 by the authors Licensee MDPI, Basel, Switzerland. This article is an open access article distributed under the terms and conditions of the Creative Commons Attribution (CC BY) license (https:// creativecommons.org/licenses/by/ $4.0 /)$.

\begin{abstract}
Every day, companies are exposed to various risks arising from their environment, and small and medium enterprises (SMEs) are the most affected. This study emphasizes innovation and resilience as the starting points to understand how SMEs are influenced by external factors which are independent of the managers' will. To date, we have seen several extreme factors that have conditioned businesses and entrepreneurs of these types of companies, such as the financial crisis of 2008. However, last year, in 2020, we saw the beginning of a worldwide pandemic: COVID-19. Thus, this research seeks to understand the extent to which this pandemic influenced the resilience and innovation of SMEs in the tourism area. Thus, eight hypotheses were raised based on four independent variables: access to finance, risk taking, working conditions, and personal network. The study of these variables was developed from an online questionnaire and in-depth interviews. After analyzing the results, it is possible to infer that the COVID-19 pandemic resulted in consequences never observed in previous crises, to such an extent that the study showed that: (1) a company's network positively influences its resilience; (2) risk taking influences innovation and resilience of these SMEs.
\end{abstract}

Keywords: innovation; resilience; COVID-19 pandemic; SMETs

\section{Introduction}

Since the beginning of 2020, we have been seeing the rise of a global crisis unlike any other in a generation. The COVID-19 pandemic has already resulted in widespread illness, death, and the recession of global economies [1]. Thus, the theme of this study emerged from the spread of the COVID-19 coronavirus at the beginning of 2020 around the world, which has had several negative consequences for all economies and countries [2].

The forecast for 2020 shows a decrease in gross domestic product (GDP) and an increase in unemployment and debt [3]. Moreover, the international tourism industry is mostly composed of small- and medium-sized enterprises (SMEs) and, in the European Union (EU), they represent $99 \%$ of all business entities [4]. Thus, this study will focus on SMEs, the key businesses responsible for making economies grow. However, there are sectors of activity more affected than others, and according to a recent study of the EY-Parthenon [5], the tourism sector is currently the most affected one around the world, in addition to being the largest export economic activity in Portugal, the country chosen as the field of study, according to Turismo de Portugal. For these reasons, the focus of this study will be the impact of the COVID-19 pandemic on SMEs, during the spread of COVID-19, but only within the Portuguese tourism sector (small and medium enterprises in tourism, SMETs).

The study is also focused on the importance of innovation and resilience within this pandemic context, since "innovation has become increasingly important for the survival 
of SMEs and for establishing a competitive advantage over their competitors" [6] (p. 22). Furthermore, Turon and Kubik [7] enhance the importance of analyzing the effect of the COVID-19 pandemic in the context of open innovation. Some authors go further and note that it has a significant impact on firms' performance [8], while others defend that it is one of the main concerns of managers [9]. The opinion of the authors is almost unanimous regarding resilience. To summarize, companies that want to survive and foster success must develop their resilience capacity because it is crucial to achieve sustainability in the long term, when reacting to unexpected events [10]. The truth is that consumers' preferences are repeatedly changing, and these companies must deliver services in such a cost-effective way that makes them capable of satisfying their customers and, at the same time, be profitable [11]. Moreover, this is a fast-growing industry that is becoming even more competitive. Therefore, companies must innovate and be more resilient during periods of economic turmoil.

Due to the reality caused by the COVID-19 pandemic, Antonioli and Montresor [12] believe that innovation is affected by the stage of the business cycle we are in, which is characterized, at this time, as a difficult and unique economic moment. It is important to mention that innovation in the tourism sector has been studied by several authors. In a recent study, Dias et al. [13] argue that most of the literature regarding this subject focuses on its needs, drivers, and obstacles, as well as its determinants. For Tajeddini [14], we can observe innovation within SMETs in a variety of ways, such as developing new strategies or encouraging employees to come up with new ideas. Others support the idea that a crisis influences the innovation process in the tourism sector as much as it influences the management perception of the future [15], which means that if the perception of the manager is negative, their predisposition to innovate will be lower. Moreover, most studies on tourism innovation are "descriptive and (or) analytical, and the need for more empirical research and quantitative evidence has widely been emphasized" [16] (p. 158).

Despite the numerous studies focused on SMETs' innovation and resilience, as mentioned above, none of them embrace these two variables in a similar context to the COVID-19 pandemic due to the simple reason that it is a unique situation. Therefore, the emergence of some studies in this field is expected within the COVID-19 pandemic context. However, such studies do not fully reflect the management and economic effects of this crisis on SMETs. Furthermore, firstly, its consequences began as a health crisis and then developed into an economic issue [17], which made various authors believe that this crisis is much worse for economies than, for example, the 2008 financial crisis [18]. This points out the gap that this study aims to fill: few studies have focused on SMETs' innovation and resilience during this unique, and never before seen pandemic crisis.

The literature reveals several aspects that may influence SMETs resilience and innovation. Among these aspects, the following are highlighted in this study: (1) the access that these companies must have to finance (access to finance) [19]; (2) the level of risk that these companies and their managers can pursue and how they deal with uncertain times [20]; (3) the working conditions in which employees are working [21]; and (4) the personal network of each business [22]. Many other aspects can influence the innovation and resilience of Portuguese SMETs. However, for the current study, these are the four fundamental aspects that will be analyzed. It is also important to highlight that in selecting four aspects, each company's reality is a singular one and outcomes can vary.

This study aims to fill the existing gap pointed out in the literature regarding rethinking the tourism sector, namely, its innovation during a crisis while adding resilience as a concept that works together with the innovation process [1,2]. This is important since it makes managers rethink old strategies and models that have been used until now. The COVID-19 pandemic can be seen as an opportunity to rethink this sector of activity and thus to innovate differently [2]. At the end of the crisis, improvements will remain, and they will be an enormous advantage $[3,23]$. Hence, with a deeper study focusing on certain variables, it will be possible to identify the main challenges that those entities are facing to innovate while being resilient during this specific moment and to propose viable solutions. 
Several theoretical and empirical objectives were established. Starting from the research question "What influences innovation and resilience on small- and medium-sized enterprises within tourism, in a pandemic context?", the general objective is to understand the factors that influence these variables the most, in a pandemic scenario, in SMEs within the tourism sector, specifically with the spread of the COVID-19 pandemic. Starting from the objective, what this study contributes is not the factors that influence innovation and resilience, but the influence of those factors within this unique and never before seen pandemic context. Specifically, it aims to understand if access to finance (AF), risk taking (RI), working conditions (WC), and personal network (NW) influence innovation (INNOV) and resilience (RES) of SMETs during the COVID-19 pandemic.

\section{Literature Review}

\subsection{COVID-19 Impacts in SMETs}

Buffa, Franch, and Rizio [24] defend that small businesses are flexible and have a strong ability to develop relationships which can be important to gain incentives (economic ones, for example) to complement their resources, which is a very important detail for their growth. However, Mittal et al. [25] support that participation among employees in what concerns the business is low. They also argue that usually SMEs are afraid of investing in new ideas, which makes them less likely to be early adopters of a given idea. Despite this fact, SMEs embody $90 \%$ of all firms worldwide [26] and are usually the major contributor to employment in most countries [27]. This is supported by the Annual Report on European SMEs of the European Commission written by Muller et al. [28]: 99.8\% of the enterprises in Europe, that Portugal is part of, were SMEs, and they were responsible for $66.6 \%$ of the employment in that continent. This idea is quite consensual throughout the existing literature. It is not by accident that these enterprises are called "the backbone of the European economy" [29] (p. 200).

SMETs are, in general, highly adaptable and self-reliant; nevertheless, in this specific pandemic crisis, the situation is beyond their control [2], perhaps because the problems they are facing have changed from a health crisis to an economic crisis [17]. The COVID-19 pandemic consequences are much worse for economies than, for example, the 2008 financial crisis [18]. Every sector suffered costs due to the pandemic, however, the tourism industry was the most harmed due to many factors. In addition, it is important to mention that the pandemic came during a period in which the liquidity of touristic firms usually experiences low levels due to seasonal demand [1].

If tourism is a vulnerable sector, so are SMETs. This type of enterprise is characterized as a labor-intensive industry and that makes them very vulnerable to market changes. These enterprises survive through low-profit margins and so small sales losses can have a huge impact on their profitability [2]. Furthermore, SMEs in general, which also englobe SMEs within the tourism sector, experience lower levels of preparation, higher susceptibility, and higher dependence on governments compared with multinationals [30].

During this pandemic, three of the main issues that these firms faced were related to lack of cash flow, the interruption of supply chains, and low market demand. This lack of cash flow can be explained by the obligation that firms must continue to pay fixed expenditures, such as salaries, rents, or loans [30]. Concerning supply chains, the disruption of chains suffered by SMETs resulted in substantially reduced production. Finally, market demand is one more significant factor for the prosperity of these enterprises. During quarantines, lockdowns, and even with only some contingency measures, the physical movement was restricted which negatively impacted consumer confidence at the time of purchasing goods and services in physical places. Thus, a reduction in private consumption spending was seen [30].

It is also possible to investigate these three issues and organize them in a timeline, which suggests that businesses experienced a four-phase process after the crisis arrived. The first phase occurs when businesses see a cash-flow reduction. The second phase comes with the disruption of the supply chain, as already mentioned, and the third was when 
businesses reopen, however, under many restrictions, such as during a lockdown, a partial lockdown, or the obligation to ensure the required social distancing. All these issues merge into a completely new situation for managers and workers. Finally, the last phase is workforce reduction [17].

However, there may be other reasons, such as people's decisions. People, in general, have been experiencing a behavioral loop in response to curbing the spread of this disease. Nevertheless, this behavior suffers many trade-offs, influenced by what individuals value the most at each moment: money, time, relationships, health, and many others. Because of these factors, many firms have faced abrupt declines in revenue, and some even risk insolvency [31]. The transition to remote work was one more factor that, for some specific businesses, had a negative impact [17]. Nevertheless, the managers' attitude and mindset play an extremely important role when facing such situations. On a micro level, SMEs were generally pessimistic about their short-term development. On the other hand, from a macro level point of view, SMEs' expectations for the economy were better. In addition, regardless of their losses, SMEs' managers still had confidence in governments to help them through this pandemic [30]. Moreover, turbulent times can also be seen as opportunities for some entrepreneurs to identify major trends during and after the pandemic and, at the same time, forecast what our society needs [32].

\subsection{Conceptual Framework}

\subsubsection{Resilience, Innovation, and Open Innovation}

Currently, small- and medium-sized enterprises' (SMEs') managers/owners must consider innovation as a key to their strategy due to the competitive advantage this can bring to business [33], and what innovation brings to peoples' lives and their businesses: new ways to improve, to be better, and to do better when facing new challenges.

Resilience is a vast concept and can be seen through different levels. For Luthans et al. [34], resilience is related to employees' ability to bounce back in the face of enormous issues. On the other hand, and from a psychological standpoint, resilience is a skill revealed when managing difficulties successfully [35]. However, it cannot be only a single action itself, but a sequence of actions that neutralize threats, including elasticity, learning, and rejuvenation [36]. Linnenluecke [37] perceives resilience as a key to overcoming external threats within organizations, such as unexpected events and extreme variations that shock organizations. The same author reveals that some organizations are not even capable of surviving such challenges, while others become stronger. Resilience is the reason why some companies have the power to respond faster to unfamiliar events [37], which is why it is seen as a crisis management tool for business stability and adaptability [38].

Innovation is a determinant factor of competitive advantage for SMEs [39,40]. It makes the pursuit of new ideas and opportunities easier [41] because it relates to the introduction of new techniques, products, and/or systems, as well as new strategies to compete within the market [42]. For Martínez-Román and Romero [43], innovation has two different dimensions: the personal characteristics of the entrepreneur and the characteristics of the organization itself. The first one regards entrepreneurs' beliefs and predispositions and the second one concerns the culture of the company. The latter is the one with the major influence on the innovation process, according to these authors.

\subsubsection{Access to Finance}

Access to finance can be intended as the part of investment and working capital subsidized by formal finance [44] and it can take different forms: grant funding, equity funding, and debt funding. It is seen as an intangible asset due to its lack of physical substance [45]. Even though it has been increasingly improving, studies still show that this remains one of the main obstacles for SMEs [46]. Regardless of the World Bank stating that one of its objectives is to invest in different strategic sectors, including tourism [47], it seems a far reality for many SMEs. 
Financial development and economic growth are coupled. Tourism is a highly volatile sector which makes it suffer high financial risks [48]. SMEs, but especially SMETs, find it difficult to obtain commercial bank financing due to many factors: lack of collateral, small cash flow, high-risk premiums, or underdeveloped bank relationships [49], as well as difficulties in obtaining credit from suppliers and financial institutions [50]. Consequently, SMETs finance themselves, namely, with retained earnings instead of debt due to the high costs of bank loans [49].

Adegboye and Iweriebor [51] believe that ease of access to finance is the biggest positive contribution to innovation among SMEs due to the leverage gained, allowing them to bounce back from uncertainty with innovation. Among other factors, such as the expansion of operations, investing in production facilities, and new staff, innovation is also a positive consequence of financing [52]. In this sense, the following hypothesis was created:

\section{Hypothesis 1 (H1). Access to finance influences SMETs' innovation.}

In addition, to undertake the challenges of a crisis and manage a chaotic business scenario, different resources are needed to convert these situations into opportunities. One of the resources needed is access to finance, which works as a shock absorber of a crisis's negative impacts $[10,23]$. Another reason pointed out by these authors is that financial resources may allow employees to stay with the company, preventing layoffs. Huang and Farboudi Jahromi [53] stated that access to finance is a critical factor for business resilience in normal times, and even more during difficult times, such as the COVID-19 pandemic. In this regard, the idea that access to financing provides a good condition to bounce back from some situations is also an indicator that it contributes to SMETs' resilience [51]. Thus, we hypothesize:

Hypothesis $2 \mathbf{( H 2 ) . ~ A c c e s s ~ t o ~ f i n a n c e ~ i n f l u e n c e s ~ S M E T s ' ~ r e s i l i e n c e . ~}$

\subsubsection{Risk Taking}

Firms that take risks are willing to accept these risks to exploit innovative opportunities and gain competitive advantages [54]. Recent studies from Hudakova et al. [55] show the key risks SMEs should take from the authors' point of view. The first three are market risks, financial risks, and economic risks. However, it seems that depending on the circumstances and the characteristics of the manager/owner, the behavior through risks could be different. For example, an experienced manager may risk more than an inexperienced one [56].

In addition, firms which are privileged enough to take on more risk, also have the greatest opportunities, and thus are more likely to be the most innovative [57]. Likewise, Games and Rendi [58] state that the risk taken by firms is a way of reducing negative outcomes from innovation. The same authors believe that risks taken can influence employees' predisposition towards innovation, which consequently will influence the innovation of the company. In addition, a study conducted by Pikkemaat [59] indicates that risk-averse behavior is a barrier to SMETs' innovation. Thus, the following hypothesis was stated:

\section{Hypothesis 3 (H3). Risk-taking attitude influences SMETs' innovation.}

Additionally, entrepreneurs who are exposed to risks are much more proactive in sustaining growth, compared with those who are not. Besides, experience-which is associated with resilience-contributes to managers' learning the best strategies to navigate risky situations [22]. Most of the time, resilience is evident when firms are exposed to some external threat, which may arrive from a risk taken by them [37]. Therefore, firms need to mitigate risks in order to be resilient and, consequently, this constructs a resilient mindset [10]. Due to this, the following hypothesis was stated:

Hypothesis $4 \mathbf{( H 4 ) . ~ R i s k - t a k i n g ~ a t t i t u d e ~ i n f l u e n c e s ~ S M E T s ' ~ r e s i l i e n c e . ~}$ 


\subsubsection{Working Conditions}

A worker within a good workplace is more excited to make their contribution to a SME's goals [60]. A good work environment is a great contributor to workers' mental and physical well-being. Companies usually focus their resources to improve social security as it is seen as a key area between employees in what concerns good conditions at work [61]. Other companies believe that pressure on competitiveness, realized by innovation, leads firms to create an environment for innovative work teams [62]. The question that must be raised is: what is a good environment, and which working conditions must be met to stimulate innovation? For Hoyrup et al. [63], employees' initiatives and autonomy are as important as the structure and conditions at work. The same authors believe that good working conditions improve a firm's ability to provide knowledge and learning processes to their workers because "learning can produce innovation" (p. 4). Therefore, the following hypothesis was created:

\section{Hypothesis 5 (H5). Company working conditions influence SMETs' innovation.}

Moreover, if good working conditions contribute to the individual well-being of each employee, it will consequently contribute to improving individual resilience and spirit. In addition, when the literature mentions working conditions, not only is it referring to the possibility of learning but also the level of income of each employee, which is another relevant influence for resilience within a business [64]. The same authors also stated that conditions at work are also measured through the level of stress experienced by employees and their response, which will also influence resilience. However, at the same time, they believe that resilience skills may reduce workplace stress. In the same way, Ojo et al. [65] consider that good conditions do influence employees' resilience. These authors highlighted that decent leadership is one factor that contributes to employees' perception of good conditions at work. Thus, the following hypothesis was formulated:

\section{Hypothesis 6 (H6). Company working conditions influence SMETs' resilience.}

\subsubsection{Personal Network}

A personal network is the social relationships associated with the sharing of knowledge and resources capable of making a business grow, or recover after a crisis, and can be measured through social capital, an essential element of open innovation [22,60]. Ooms et al. [66] believe that geographical proximity, institutional proximity, and cognitive and social proximity can be determinant factors in building a network. Other authors go further and affirm that "friendship is viewed as the ultimate level of relationship in the trusted network" in a business context [67] (p. 4). The same authors also specified that a strong network differs in the level of closeness, trust, mutual respect, and commitment.

The concept of networking is crucial and a key success factor for SMEs, as Gronum et al. [68] considered. Thus, these authors believe that a network's impact on firm innovation means more resources and knowledge. Moreover, Ioanid et al. [69] defend that networks bring benefits to the innovation process. Therefore, this type of enterprise needs to build strong networks due to their small and medium sizes, concluding that a week network is a limitation of many SMETs to pursue a competitive advantage [70]. Thus, we hypothesize the following:

\section{Hypothesis 7 (H7). Company personal network influences SMETs' innovation.}

On the one hand, Iborra et al. [71] argue that to be resilient is to be able to recover from a difficult and stressful event. On the other hand, Sadri et al. [72] show that a strong network, as well as higher levels of social capital, have a positive impact on the recovery of entities from disasters. In an open innovation context, if those social relationships mean that a manager/owner has more resources available to recover from a crisis [22], they can, at 
the same time, promote resilience and increase the probability of prospering after a period of crisis. This author suggests that one of the biggest influences of resilience is personal network, which goes in line with the idea that a strong network supports companies during a crisis and helps them recover faster reducing uncertainty through appropriate strategies, better agility, and adaptability [10]. Thus, we stated the below hypothesis:

Hypothesis 8 (H8). Company personal network influences SMETs' resilience.

\subsubsection{Conceptual Model}

Concerning the theoretical concepts discussed above as well as the hypotheses presented in this chapter, the following conceptual framework was developed to analyze the subject in more detail (Figure 1).

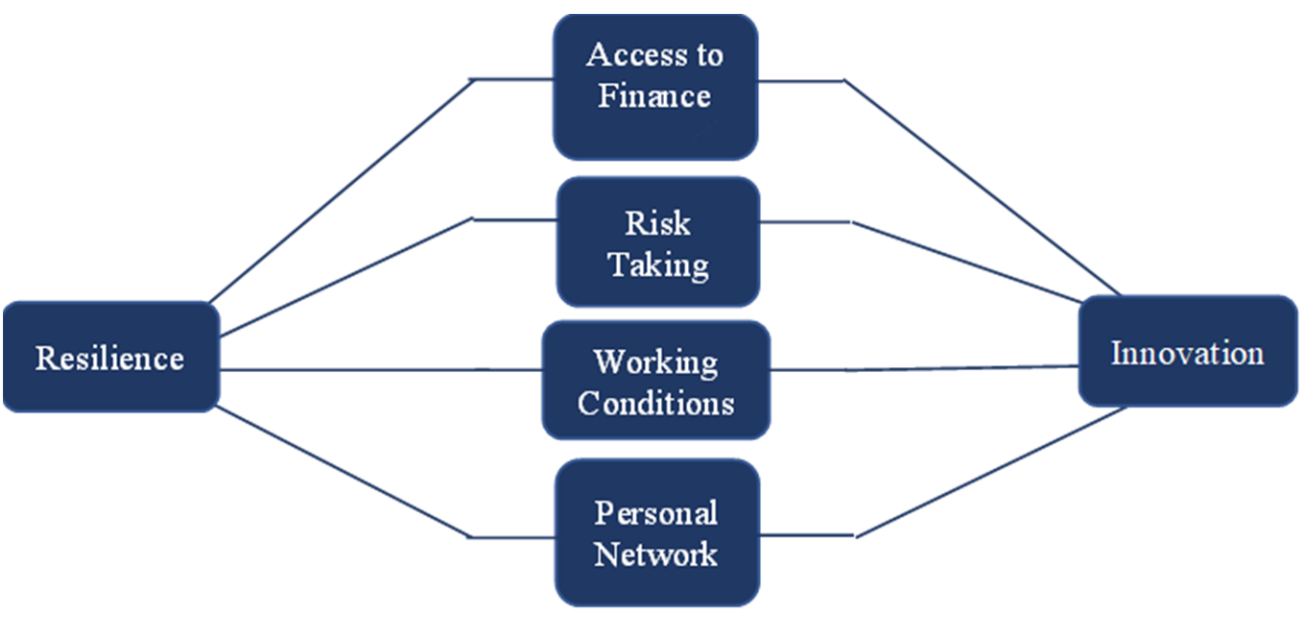

Figure 1. Conceptual model.

The proposed model allows us to understand if there is any influence of the variables access to finance, risk taking, working conditions, and personal network on SMETs innovation and resilience.

\section{Methodology}

\subsection{Research Approach and Design}

This is a deductive study, meaning that the stated hypotheses are based on theories and literature that already exist [73]. The deduction method consists of starting from the general and moving into the particular, which means starting from a theory that will lead to a hypothesis construction. The present study uses the two main types of information collection, namely, primary data and secondary data. Secondary data is data used by someone other than the author who carried out the research for primary use. This concept leads us to primary data, which is data collected by someone for their own use [74]. On the one hand, in this study, the primary data covers the online questionnaire and interviews that have been conducted. On the other hand, the secondary resources consist of bibliographic research that encompasses scientific articles, magazines, books, and websites.

Concerning data collection, we can identify two different types of data: qualitative data and quantitative data. In this study, an online questionnaire was used as a quantitative method and was sent to the managing directors of SMETs or owners of the same types of enterprise. Additionally, the study combines this with a qualitative method that allows a deeper understanding of concepts that cannot be quantified. In the case of this study, in-depth interviews with content analysis and a sample of entrepreneurs allowed us to better understand how these entrepreneurs think. In summary, the quantitative method provides certainty and the qualitative method provides depth to this study. 
Regarding the type of investigation, this study is characterized as being a predictive investigation due to the testing of several variables to understand if, and how, they influence innovation and resilience of SMETs during a severe crisis, such as the COVID-19 pandemic. Moreover, it is a sequential explanatory investigation due to the use of qualitative data supporting the quantitative data [75].

Focusing on the sampling technique, this can be separated into probabilistic or nonprobabilistic. The probabilistic sample technique ensures that the probability of selecting a determined population member is equal to selecting all the others, which is the same as saying that the selection is made randomly. Conversely, the non-probabilistic sample technique is not based on a random selection, but on a selection based on the characteristics of the investigation itself, so some population members are more likely to be selected than others [76].

Additionally, the sample used was chosen by convenience. A convenience sample is a sample whose selection criteria is related to pre-defined characteristics formulated by the investigator, for example, age or gender related [77]. Such characteristics are advantageous for the theme of the study, making it easier to obtain a reliable outcome. Finally, this method concerning collecting data from a population, a sample group, is called the data collection method. Regarding this field, this study will use a quantitative and a qualitative method to try to achieve the investigation purpose [78].

To collect data, an online questionnaire was built and posted through the Google Forms platform. This questionnaire was sent to the managing directors of SMETs or owners of these types of businesses. The target population of the survey, within SMETs, includes hostels, restaurants, tours, and museums in Portugal (the field of study chosen).

\section{Sample Characterization}

The population of this study is composed of (1) small- and medium-sized enterprises in Portugal and (2) SMEs within the tourism sector. The focus on the tourism sector is justified by the fact that it was the most affected sector during this pandemic, as explained in the introduction.

The survey has a total of 26 questions and received 103 responses. To characterize this sample, it was decided to analyze the sociodemographic variables: number of employees of each SMET, country, and region where each SMET is located, and the number of innovative products/services launched during 2020. From the total of 103 questionnaires answered by SMETs, most of them have between 0 and 10 employees, corresponding to $68.9 \%$ of the total $(\mathrm{n}=71)$. Regarding between 11-50 and 51-250 employees, the results show a total of $26.2 \%$ $(\mathrm{n}=27)$ and $4.9 \%(\mathrm{n}=5)$, respectively. In Portugal, the main part of the sample population has offices in Lisbon, representing $34 \%$ of the inquiries $(n=35)$. The other regions in the sample include offices based in Madeira Island (8.7\%), Algarve (13.6\%), Alentejo (6.8\%), the center of Portugal (13.6\%), Azores Island (8.7\%), and Porto (14.6\%).

Finally, the survey shows that many enterprises did not innovate during 2020, namely $23.3 \%(\mathrm{n}=24)$. However, the majority of SMETs, 62.1\%, had between 1 and 5 innovation products/services during this specific year $(n=65)$. The rest of them indicated that they had between 5 and 10 or even more than 10 innovative products/services, corresponding to $7.8 \%(n=8)$ and $6.8 \%(n=7)$, respectively.

\subsection{Quantitative Study}

To collect data to carry out the present study, an online questionnaire was constructed. The target population of the survey is the small- and medium-sized enterprises in tourism (SMETs), such as hotels, restaurants, tours, and museums in Portugal. The survey aimed to reach SMETs that had high levels of innovation since the beginning of 2020 as well as those with low levels of innovation during this pandemic scenario. Thus, it was possible to understand the differences between both types and determine what is missing in the SMETs that did not innovate. The questions were based on surveys from other authors; however, some changes were made. For instance, it was necessary to eliminate some of 
the questions when studying a specific variable, some statements were rephrased, and all questions were translated into Portuguese because the respondents were Portuguese SMETs.

Before starting to build the questionnaire, a literature review was written having in mind the variables and subjects that would take part in the online survey. Besides, the use of other authors' questions regarding each variable in the study enhances the reliability and quality of the results. Additionally, there are some features pointed out by Codó [78] that make a successful questionnaire: good planning of the sample; the fact that it must not be too long; the phrase construction, which should be appropriate for the specific survey target; clarity; and instructions on how to fill it in.

The questionnaire used in the present study is mostly composed of closed questions with some exceptions. Nevertheless, there are some introductory questions, for example, one question asks where the SMET is located. All other questions which are applied to each variable were measured on specific authors' scales that can be consulted in Appendix A. Regarding the treatment of the data, PLS software was used. Once more, Appendix A provides the variables which are being studied with the survey, each item that will be used, the measures of each independent variable, and the respective authors.

Lastly, it is important to highlight that the survey respected all the inherent ethics: it guarantees the confidentiality and anonymity of each respondent, which increased their confidence to be as honest as possible [78]. Besides, all the participants were well informed about the purpose and uses of this study, as well as their voluntary participation.

\subsection{Qualitative Study}

To increase the quality and depth of the data collection, in-depth interviews were carried out, with content analysis and a sample of entrepreneurs. This type of interview allows the investigator to inquire about participants' beliefs and opinions. This approach also provides the investigator with the option to ask participants to clarify or elaborate on some specific topic [79].

Through this second method, it was possible to understand the way managers think and conduct a deeper analysis, and not only by numbers. In this methodological approach, the strategy used was data saturation, which allowed the study to have the most diverse and useful information possible. The target population of this method was SMETs in Portugal, but different from the ones used in the questionnaire. The interview questions related to the questions from the questionnaire. Moreover, due to COVID-19, all interviews were conducted by phone call and recorded with the agreement of each participant.

\section{Results and Discussion}

This study combines a quantitative method with a qualitative one, using a mixed method. The quantitative method is an online questionnaire and the qualitative one consists of in-depth interviews, with content analysis, and a sample of entrepreneurs. Through this second method, it was possible to understand the way participants' think through a deeper analysis, and not only superficial. In this methodological approach, the strategy used was data saturation, which enabled the collection of more diverse and useful information. The target population for both methods was Portuguese SMETs.

\subsection{Qualitative Study Results}

The conclusions drawn from the interviews were in accordance with the quantitative results. All five interviewees agreed that financing was not a contributor to their business innovation during the COVID-19 pandemic. The manager of restaurant A, located in Lisbon, mentioned two clear reasons for this. Firstly, "the huge cost of time that we spend waiting for that financial help, and the fact that many of these businesses were not able to have this privilege due to being small". In his opinion, even though they did not have financial help, many of these enterprises were able to innovate, which is why he did not consider this correlation to be accurate. Similarly, he also considered financing to not have 
any influence on the business's resilience. The main reason indicated was the fact that moments where resilience was most crucial were during lockdowns and, with this point, the interviewee stated that it was during this time that other things, instead of money, became more important to continue the business. In the opinion of the manager of restaurant B, in Azores Island, "the thing that influenced resilience the most during this time was my mindset, as a manager, during quarantine. Money would solve some problems but would not create resilience".

Concerning risk taking and how such an attitude influences, or not, innovation and resilience, all the respondents shared the same opinion. All of them agreed that taking risks forced them, as managers, and their employees to be more innovative. Moreover, the manager of restaurant B highlighted that it is inevitable that innovative ideas come from risky actions because such actions are necessary to survive these kinds of situations. Concerning resilience, their opinions did not change. In the words of the manager of restaurant B, "entrepreneurs will increase their experience only if they are willing to be exposed to risks", which will inevitably contribute to build a resilient mindset. This manager concluded by saying that for those that play it safe, there is no need to be resilient because they are in their comfort zone.

However, contrary to this, interviewees did not consider working conditions to be a significant influence in innovation and/or resilience. Even though most of them recognized that this factor helps in many parameters, such as the ability to preserve human resources, which is an indicator of good conditions for that specific work, they did assume that this can influence the innovation or resilience of SMETs. However, it was clear that none of them had a well-organized opinion about this relation.

But if working conditions were not clear for them, the opposite happened with business's network influences in innovation and resilience. The manager of restaurant B argued that this crisis was transversal to the whole supply chain; thus, it was the cooperation among all participants and good relationships between them that made it possible to bounce back from such difficult times. Therefore, and influenced by companies and people around them, all the interviewees had no doubts that their resilience increased a lot when working with people with whom they identify professionally.

\subsection{Quantitative Study Results}

A structural equation modeling (SEM) was used to test the conceptual model of this study. This technique combines factor analysis with regression and the main goal is to design paths between variables to build and then accept, or reject, a theory. Namely, the partial least squares (PLS) method was used through SmartPLS software [80].

Appendix A provides the variables that were being studied within the survey, each item used, the measures of each independent variable, and the respective authors. In the present study, the following data analysis methods were used: Cronbach's alpha reliability test, composite reliability test, average variance extracted, R-squared, Fornell and Larcker criterion, heterotrait-monotrait ratio, structural path coefficients, and collinearity statistics. They will be described in more detail in the following pages.

To achieve the proposed objectives, a quantitative method was used, namely, an online questionnaire with a non-probabilistic convenience sample. Then, it was sent to the managing directors of SMETs or owners of the business, such as hotels, restaurants, tours, and museums in Portugal.

\subsubsection{Validity and Reliability}

We measured the reliability and validity of the measurement model, and secondly, we assessed the structural model. Concerning the quality of the measurement model, we examined the following indicators: reliability, convergent validity, internal consistency reliability, and discriminant validity [81]. Internal consistency reliability was confirmed because the constructs' Cronbach's alpha (CA) and composite reliability (CR) values ex- 
ceeded the cut-off of 0.7 (with a minimum value of 0.712 and 0.812 , respectively) [81], which enhances an adequate internal consistency (Table 1).

Table 1. Cronbach's alpha, composite reliability, average variance, correlations, and discriminant validity.

\begin{tabular}{cccccccccc}
\hline & CA & CR & AVE & AF & INNOV & NW & RES & RI & WC \\
\hline AF & 0.753 & 0.888 & 0.799 & $\mathbf{0 . 8 9 4}$ & 0.144 & 0.100 & 0.206 & 0.168 & 0.089 \\
INNOV & 0.920 & 0.944 & 0.807 & 0.123 & $\mathbf{0 . 8 9 8}$ & 0.263 & 0.215 & 0.331 & 0.128 \\
NW & 0.712 & 0.845 & 0.732 & 0.075 & 0.201 & $\mathbf{0 . 8 5 6}$ & 0.204 & 0.175 & 0.390 \\
RES & 0.891 & 0.914 & 0.606 & 0.174 & 0.198 & 0.159 & $\mathbf{0 . 7 7 8}$ & 0.259 & 0.187 \\
RI & 0.772 & 0.864 & 0.681 & 0.019 & 0.309 & -0.061 & 0.238 & $\mathbf{0 . 8 2 5}$ & 0.143 \\
WC & 0.785 & 0.812 & 0.517 & -0.057 & 0.095 & 0.250 & -0.144 & 0.105 & $\mathbf{0 . 7 1 9}$ \\
\hline
\end{tabular}

CA-Cronbach's alpha, CR-composite reliability, AVE-average variance. Bold numbers in diagonal are the square roots of AVE. Below the diagonal elements are the correlations between the constructs. Above the diagonal elements are the heterotrait-monotrait ratios.

The results showed that the standardized factor loadings of all items were above 0.6 (with a minimum value of 0.62 ) and were all significant at $p<0.001$, which provided evidence for the individual indicator reliability [81].

Convergent validity was also confirmed by observing $C R$ values higher than 0.70 and by all average variance (AVE) values that exceeded 0.50 [82]. Regarding the discriminant validity, this one was evaluated using the Fornell and Larcker criterion and the heterotraitmonotrait ratio (HTMT) criterion [81]. The first criterion requires that the construct's square root of AVE (revealed on the diagonal with bold values in Table 1) is greater than its biggest correlation with any construct [83]. Table 1 shows that this criterion was accomplished for all constructs. Regarding the second criterion, we can observe that the HTMT is below the conservative threshold value of 0.85 , providing even more evidence of discriminant validity [81].

\subsubsection{Structural Model}

Before assessing the structural model, we analyzed the collinearity [81], with values between 1.00 and 1.15, which is below the indicative critical value of 5 projected by Hair et al. [81]. Consequently, these values showed that there is no collinearity.

The coefficient of determination $\mathrm{R} 2$ for the two endogenous variables of resilience and innovation were $15.6 \%$ and $15.4 \%$, respectively. Thus, these values exceeded the threshold value of $10 \%$ [84]. The $Q 2$ values for all endogenous variables ( 0.109 and 0.060$)$ were above zero which revealed, once again, the relevance of the model [84]. In Figure 2 it is possible to see the path coefficients out of parentheses and the $p$-values in parentheses.

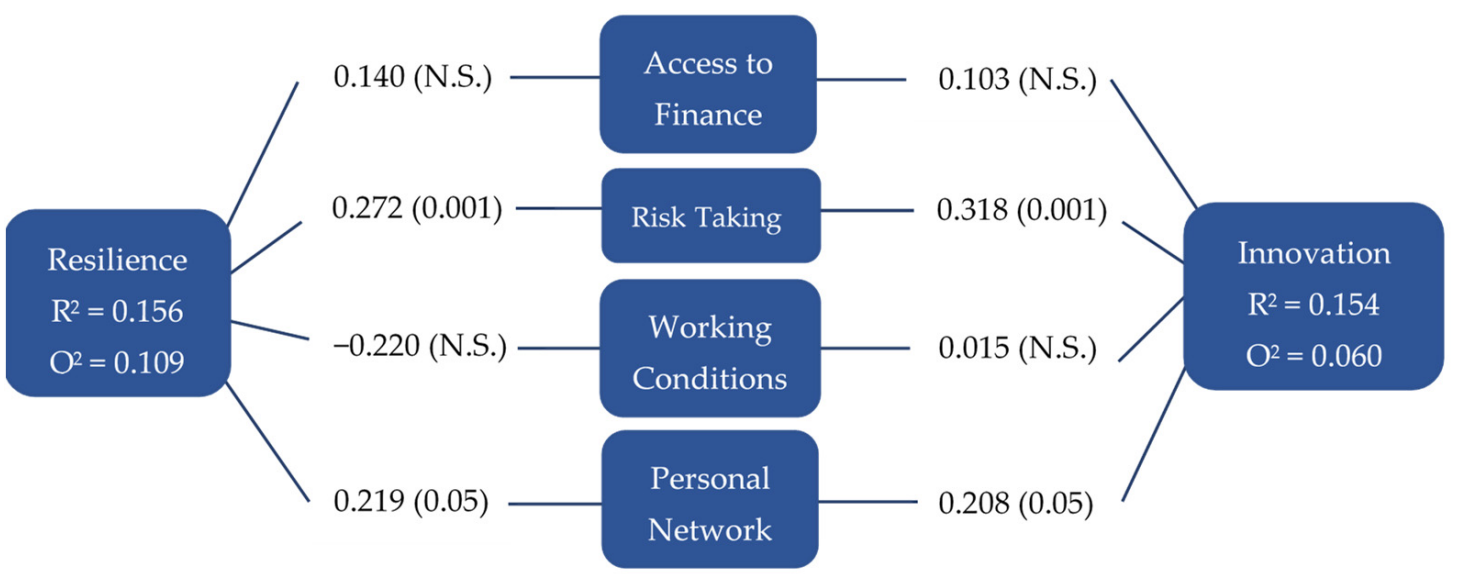

Figure 2. Research Model with PLS-algorithm and bootstrapping results. 


\subsubsection{Hypotheses Test}

On the one hand, Table 2 shows that risk has a significant positive effect on innovation $(\beta=0.318, p>0.001)$ and on resilience $(\beta=0.272, p>0.01)$. Moreover, that personal network has a significant effect on innovation $(\beta=0.208, p<0.05)$. On the other hand, the same table shows that access to finance and working conditions do not influence innovation or resilience and that personal network does not have any impact on resilience.

Table 2. Structural model assessment.

\begin{tabular}{ccccc}
\hline & Path Coefficient & $\begin{array}{c}\text { Standard } \\
\text { Deviation }\end{array}$ & T Statistics & $p$ Values \\
\hline AF-INNOV & 0.103 & 0.099 & 1.038 & N.S. \\
AF-RES & 0.140 & 0.110 & 1.278 & N.S. \\
NW-INNOV & 0.208 & 0.104 & 2.000 & $p<0.05$ \\
NW-RES & 0.219 & 0.128 & 1.720 & N.S. \\
RI-INNOV & 0.318 & 0.090 & 3.545 & $p>0.001$ \\
RI-RES & 0.272 & 0.098 & 2.774 & $p>0.01$ \\
WC-INNOV & 0.015 & 0.114 & 0.135 & N.S. \\
WC-RES & -0.220 & 0.215 & 1.020 & N.S. \\
\hline
\end{tabular}

It is important to highlight some findings that arose from the questionnaire and the interviews of SMETs managers/owners. More than 50\% of the respondents to the questionnaire revealed that employees are not penalized if they have new ideas without success. Moreover, almost half of them said that innovation is promptly accepted when managing a project, despite being slightly pessimistic about their short-term development [30]. Still, regarding innovation, the study results show that almost $50 \%$ of the respondents stated that despite the risk associated, their enterprises promote innovation among their culture and, finally, nearly a half of the respondents said that, as managers, they are continually looking for new ideas, products, and services. These are some of the results from the questionnaire, which are corroborated by the interviews conducted on this topic due to the consensus found among the interviewees, such as the opinion of the manager of restaurant A. He stated that, presently, businesses that do not innovate will close in the long term. Thus, it seems that entrepreneurs are conscious and share the same opinion as the authors that innovation brings competitive advantage to businesses [33] by increasing the productivity and performance of tourism enterprises [85].

Regarding resilience, the questionnaire responses put in evidence that more than $50 \%$ of the managers of the sample used have pre-defined practices to handle a crisis, which contributes to help firms recover from difficulties [23]. However, only a few, approximately $28 \%$, said that they test these procedures, even though more than half of the respondents said that all employees are aware of contingency plans for incidents. In addition, a few specific trainings to put these plans into practice. This combined with the fact that this crisis came during a period in which the liquidity of the tourism sector is usually low (due to seasonal demand), which contributed to testing their firm's resilience. These are some of the reasons that made many authors believe that the consequences of the COVID-19 pandemic are much worse for economies, than, for example, the 2008 financial crisis [18]. The main challenges that obliged companies to be resilient were lack of cash flow, interruption of supply chains, and low market demand [33]. Once more, the conclusions drawn from the qualitative method were unanimous and in agreement with the questionnaire results.

As already stated, what this study contributes is not the factors that influence innovation and resilience, but the behavior of those factors within this unique and never before seen pandemic context. Divisekera and Nguyen [16] make it clear that the existing literature is not enough to deal with the COVID-19 pandemic situation. So, the present study aimed to understand if access to finance (Acce_Fin), risk taking (Risk), working conditions (Work Cond), and personal network (NetW) influence innovation (Innov) and resilience (Resil) of SMETs during the COVID-19 pandemic. Hence, some hypotheses were not supported, 
and others accepted. It makes sense that this study rejects some of the hypotheses because there is no similar crisis such as this one, so there are very specific and new constraints never before considered. Moreover, as Al-Fadly [17] stated, it is also important to bear in mind that this crisis is a unique situation perhaps since it began as a health crisis and then escalated into an economic crisis. In the opinion of Baldwin et al. [86], this crisis is different from the previous ones due to the others affecting countries that were far less economically centered and dependent on each other, at that time.

In summary, and answering the research question directly, what influences innovation and resilience on SMETs in this unique pandemic crisis is: (1) a risk-taking attitude, which influences both variables, and (2) a company's personal network, which influences innovation. Those relationships are positive ones, which means firms that adopt a risk-taking attitude will find innovation and resilience easier to pursue. Besides, the ones with a quality network will also find it easier to innovate.

Considering all the hypotheses created above, Rupeika-Apoga and Solovjova [49], Adegboye and Iweriebor [51], and Fowowe [52] believe that financing contributes positively to SMEs' innovation. Fowowe [52] defends that with good financing conditions, it is easier to develop new products and services and, therefore, to innovate. Adegboye and Iweriebor [51] came to the same conclusion when arguing that this factor is the biggest influence concerning an innovation mindset. Thus, it was defined, as H1, that access to finance influences SMETs' innovation. However, the results of the present study are not in accordance with the authors' conclusions. The study's quantitative results show from the values of $\beta$ and $p$-value $(\beta=0.103, p=$ N.S.) that access to finance does not influence, positively or negatively, the innovation of these enterprises. To better understand this finding, interviews were made with some top managers of SMETs in Portugal. From the point of view of the manager of restaurant A, financing was not a contributor to innovation, for two main reasons. The first one was the large amount of time that businesses spent waiting for financial support and the second one is the fact that many of them were not able to access financial support due to being a small business. They have, nonetheless, innovated.

It was not only shown that access to finance influences innovation, but it also influences resilience. Huang and Farboudi Jahromi [53], Adegboye and Iweriebor [51], and Giancotti et al. [10] defend that resilience is influenced by the financing conditions that each SME has. Namely, Huang and Farboudi Jahromi [53] argue that during difficult times, such as this pandemic crisis, the access of SMEs to finance is even more important compared with more economically prosperous times. Adegboye and Iweriebor [51] complete this idea by saying that finance is a way to overcome these moments and financial resources are crucial to businesses' recovery [10]. However, hypothesis two was rejected, H2: Access to finance influences SMETs' resilience. This study rejects $\mathrm{H} 2$ because the conclusions are not in accordance with the authors' ideas. The quantitative results show a non-significative $p$-value and a $\beta$ equal to 0.140 , which indicates that access to finance does not influence the resilience of SMETs. Moreover, all interviewees agreed that access to finance does not influence business's resilience in the COVID-19 pandemic, since the moments where it was most crucial to be resilient were related to lockdowns and when the restrictions were first lifted. The manager of restaurant B stated that even though liquidity is important, during this time what influenced resilience was the owner's mindset during quarantines, while businesses were closed, and after that, when they started reopening, although with plenty of restrictions. Money would solve some problems, but not this specific one, he said.

Even though neither innovation nor resilience seems to be influenced by financial support, Nanda and Rhodes-Kropf [57], Games and Redni [58], and Pikkemaat [59] believe that both variables are impacted by a risk-taking attitude. Nanda and Rhodes-Kropf [57] consider that taking risks is a privilege that not all firms have. Consequently, being riskaverse is a huge barrier to innovation [59]. Therefore, the ones which have that privilege can seize the greatest opportunities and, consequently, are more willing to innovate. Moreover, as a complement to this idea, Games and Redni [58] believe that a risk-taking mindset by the firm motivates its employees and thus they are more predisposed to have innovative 
ideas. So, the third hypothesis was defined as H3: Risk-taking attitude influences SMETs innovation. This goes in line with the opinion of the manager of restaurant $\mathrm{A}$, who believes that the COVID-19 pandemic forced him, as manager, and all his employees, to be much more innovative. Moreover, he believes that this is linked to the need to take risks and sees that as something that will be mandatory for every touristic business to survive in the future. Similarly, the manager of restaurant B revealed that they were inexperienced when they opened their restaurant, so for them, building their business required a risky attitude. Everything that proceeded this was also risky and, inevitably, innovative ideas came from this mindset. Finally, in the present study's results, it is verified by the value of $\beta(0.318)$ and the $p$-value $(p<0.001)$ that there is a significant positive influence between a risk-taking attitude and the innovation of these enterprises.

As already mentioned, having a risk-taking attitude influencing resilience was another idea defended by many authors. Thus, a hypothesis was built as H4: Risk-taking attitude influences SMETs' resilience. Herbane [22] stated that workers who are exposed to risks are much more proactive compared with those who do not, which enhances their resilience behavior. Therefore, this skill is put in evidence when facing risks [37] and, simultaneously, while pursuing and mitigating risks, they are building a resilient mentality [10]. Furthermore, when companies adopt a risk-taking attitude, they automatically start to gain experience, which also helps to build a resilient mindset and behavior, by being much more prepared for each specific and new situation. Moreover, the results of this study are in accordance with this. The study's quantitative results show from the values of $\beta$ and $p$-value $(\beta=0.272, p>0.001)$ that there is a significant positive influence between a risk-taking attitude and SMETs' resilience. Concerning the qualitative study, the manager of restaurant $B$ shares the same opinion as to the one related to innovation, and thus he agrees that a risk-taking attitude influences SMETs' resilience in the way that businesses will be able to improve and increase experience only if taking risks. For those that play it safe, there is no need to be resilient because they are in their comfort zone, and everything can be easily predicted.

However, when speaking about working conditions and their influence on SMETs' innovation and resilience, the literature is not in line with the findings of the present study. The fifth hypothesis states that the company's working conditions influence SMETs ${ }^{\prime}$ innovation, showing a positive relation. The studies of Držajić and Vega [61], Mizla [62], and Hoyrup et al. [63] support this idea, thus leading to H5: Company working conditions influence SMETs' innovation. More specifically, these authors believe that good working conditions are essentially related to having the possibility to learn and to make the work environment a positive place for the mental and physical well-being of workers. On the one hand, Držajić and Vega [61] believe that improving social security is one of the main contributors to good conditions at work. On the other hand, Hoyrup et al. [63] state that employees' autonomy is one of the most relevant factors. Yet, the interviews carried out showed that in the opinion of entrepreneurs, good working conditions during times such as these are also related to giving guidelines, training, and preparation to appropriate procedures in case of crisis and difficulties. Most of the interviewees believe that with this type of concern, companies are better prepared to preserve their human resources, which contributes to the parameter of working conditions. However, they do not find this enough to consider that good working conditions have a positive influence on innovation, considering this relation not significant. Likewise, with the quantitative results of the present study, this hypothesis was rejected. The $p$ value shows a non-significative value and $\beta$ equals 0.114 , which indicates that working conditions do not influence innovation.

Even though the fifth hypothesis was rejected, the authors' opinions were enough to build the sixth hypothesis, defended by Athota and Malik [64] and Ojo et al. [65]. H6 was stated as: Company working conditions influence SMETs' resilience. Athota and Malik [64] believe that we can measure the working conditions by the level of stress that workers experience, which consequently will influence their resilience. Ojo et al. [65] emphasized this positive relation but mentioned that the existence of a good team leader is the main 
factor for employees to consider the working place a good environment. However, this hypothesis was rejected by the quantitative results of the present study. The value of $p$ is not significant and the value of $\beta$ does not support this statement. Furthermore, none of the top managers interviewed seemed to have a clear, constructed idea and opinion regarding this relation between good working conditions and resilience.

Another hypothesis was proposed at the beginning of this study. H7 was stated as: Company personal network influences SMETs' innovation. Gronum et al. [68], Ioanid et al. [69], and Lopes et al. [70] are some of the authors who defend this relation. Gronum et al. [68] consider that a good network is crucial to every business, namely, in what concerns innovation due to the availability of more resources and knowledge of what a huge and quality network means. This idea is corroborated by Ioanid et al. [69]. Moreover, company size (small and medium) is a factor that makes it almost mandatory for these enterprises to have a strong network, otherwise, it will be hard for them to innovate and gain some competitive advantage [70]. The quantitative results of the present study also enhanced this relation, showing $\beta=0.208$ and a significant $p$-value $>0.001$, the present study accepts H7. Additionally, the interviews carried out show that most of the top management interviewees believe that a business's network influences innovation. The manager of restaurant $B$ justifies this with the fact that this crisis was transversal to the whole supply chain. Thus, many supply chain participants had difficulties. Likewise, the entrepreneurs believe that good relationships within the personal network of the business were probably built before the COVID-19 pandemic. Therefore, it is a solid and long relationship.

The last hypothesis stated is the one that predicts a positive influence of a company's personal network on a SMET's resilience. Iborra et al. [71], Sadri et al. [72], Herbane [22], and Giancotti et al. [10] are the authors who defend this theory through their studies. It was stated as H8: Company personal network influences SMETs' resilience. These authors share the idea that a good network helps in the recovery from great disasters because those relationships mean that the enterprise has more resources and knowledge available to overcome that specific situation. These are factors that increase the resilience of a company. However, the results of this study are not in agreement with this literature. This study's quantitative results show from the values of $\beta$ and $p$-value $(\beta=0.219, p=$ N.S. $)$ that a company's personal network does not influence, positively or negatively, the resilience of SMETs. To provide even more credibility to the questionnaire's results, interviews were conducted with some top managers of SMETs in Portugal. Similarly, all managers interviewed agreed that a company's personal network does not influence a SMET's resilience. Thus, H8 was not supported by the findings of the studies.

\section{Conclusions}

\subsection{Theoretical Contributions}

This study addresses the innovation and resilience of SMETs during a unique crisis, never seen before, and at the same time, an economic and health issue. There are already many studies and findings that address what influences these two important business characteristics, not only for multinationals but also for SMEs, and even within the tourism sector. However, the present study brings all of these into something new-the COVID-19 pandemic crisis, showing that the circumstances and the social context can change everything.

The study showed that what influences SMETs' innovation and resilience during this time differs from what was already found before the pandemic. Even the 2008 financial crisis did not have such a huge impact on economies and businesses and therefore the results of the study accepted some known ideas but rejected others.

It was concluded that financial help was not preponderant to companies' innovation and resilience due to the constraints caused by quarantines and lockdowns when worse issues have appeared. Another idea already stated in the literature and not corroborated by this study was the positive relationship between good working conditions and, once again, SMETs' innovation and resilience. Finally, even though the study found a company's 
network to be very useful for open innovation, this was not the case for resilience. In the case of open innovation, the importance of the personal network was found to be very important, representing an extension of existing knowledge in the field of open innovation $[7,19]$. The study concluded that during the COVID-19 pandemic, companies did not feel influenced by their network behavior, as happens in other crises and as was theoretically expected. However, the relationship with other service providers is important for tourism products, namely, transportation services, which were found to be influenced by the pandemic $[87,88]$. Moreover, the present study proved that a risk-taking attitude and an SMET's network were important factors for innovation/resilience and innovation, respectively.

\subsection{Managerial Implications}

Considering the findings of this study, it is possible to set a list of guidelines for today's managers of SMETs. However, the following lines will highlight the two principal ones. Firstly, it is undoubted that managers must encourage a risk-taking attitude amongst all employees. Competitiveness is increasing every year within this sector, and even more among SMEs; thus, companies which prefer to play it safe will not be able to foster better opportunities or be competitive in the market. A risk-taking mindset leads to construction of an innovative and resilient culture. Therefore, managers who fail to understand this point will probably see their businesses closing in the long term.

The second point to keep in mind is that managers must have a good relationship with their professional network. Relationships and people are the most important resource that a company can have, not only in prosperous times but also during the hardest periods. Thus, it is suggested that this is a crucial point when making business: to nurture all the relationships beyond business lines from day one, creating a supportive environment for open innovation. Value is not added unless managers remember this even when they do not need it the most. Good relationships are something that take time to build, so managers must consider this from the beginning.

In addition to these two main points, it is crucial that managers encourage their employees to think outside of the box and therefore to contribute to the launch of new products and services. To implement this, it is important to keep in mind that many of these innovations will fail, however, this is a necessary part of achieving success. For these reasons, it is important to clearly define the strategic orientation towards open innovation [89].

\subsection{Limitations and Future Research}

Nevertheless, it is possible to mention some limitations, such as the sample size used in the questionnaire. The study counted only 103 contributions due to the specificity of the sample characterization. For future research, it is suggested to amplify this sample. In addition, it is suggested not to use the convenience method when choosing the sample, as was used in this study. It was not possible to use tools, such as the margin of error or the confidence level, to measure the accuracy of the results due to the use of a convenience method.

Besides, not only the quantitative study but also the qualitative study showed that the variable "working conditions" can be, in future studies, considered with more detail and better analyzed, since the results of both methods were not conclusive. The fact that this study is focused only on one industry-tourism-may also be considered a limitation; thus, it is not possible to generalize the results to other sectors that have also been affected by COVID-19. Therefore, the opportunity for researchers to use this study to start investigating the same topic but in different sectors of activity exists. Finally, it would be interesting to expand the field of study to more countries, rather than only Portugal, and for a longer period. 
Author Contributions: Conceptualization, Á.L.D. and I.C.; methodology, Á.L.D. and I.C.; software, L.P.; validation, R.L.C. and R.G.; investigation, I.C.; resources, L.P. and R.L.C.; data curation, Á.L.D.; writing—original draft preparation, I.C. and R.G.; writing—review and editing, Á.L.D.; funding acquisition, L.P. and R.L.C. All authors have read and agreed to the published version of the manuscript.

Funding: This research received no external funding.

Institutional Review Board Statement: Ethical review and approval were waived for this study, since written informed consent was obtained for the in-depth interviews before each session. In the survey, a link to the online survey platform was sent by social media and the partners' social media, and at no times was contact established between researchers and participants. Moreover, the interview script and the questionnaire did not obtain or include any personal information or records. As such, all data accessible to the researchers were stripped of respondents' names, addresses, and birth dates and cannot be traced.

Informed Consent Statement: Informed consent was obtained from all subjects involved in the study.

Data Availability Statement: Data available upon reasonable request to the corresponding author.

Conflicts of Interest: The authors declare no conflict of interest.

\section{Appendix A}

Variables, Items, and Authors:

\begin{tabular}{lcl}
\hline $\begin{array}{c}\text { Independent } \\
\text { Varibales }\end{array}$ & Items & Authors \\
\hline
\end{tabular}

1. People are penalized for new ideas that do not work;

(Henri, 2006)

2. Innovation is readily accepted in program/project

$\begin{array}{ll}\text { Innovation } & \text { management; } \\ \text { 3. Technical innovation (research results) is readily }\end{array}$

$1=$ "not at all" and $7=$ "to a great extent".

The higher the number the accepted;

higher the degree.

It was changed to $1=$ "totally disagree" and

4. Innovation is perceived as too risky and is resisted;

$7=$ "totally agree".

5. Management actively seeks innovation and ideas.

(Lee, Sameen, and Cowling, 2015), with an adaption in the period of time (7 months instead of 12 months).Question 1: Yes or No

6. Have you tried to obtain finance for your business Question 2: 1 = firms which had trouble getting finance from the first source they tried; 2 = firms which did not get all the finance they needed from the first source they tried; 3 = firms which did not manage to get any finance from the first source they tried; $4=$ whether firms fail to obtain finance from any source. We decided to add option number $5=$ the company managed to obtain financing on their first attempt.

Access to $\quad 7$. If yes ... Did you have difficulties obtaining this Finance finance from the first source? (Choose which level of difficulty).

(Herbane, 2019)

$0=$ absent (Score: $0-7$ )

The higher the number the higher the degree.

It was changed to $1=$ "totally disagree" and $7=$ "totally agree".
13. The business introduced incident planning because of our contracts with customers and/or suppliers;

14. The business has certification for risk management. 


\begin{tabular}{|c|c|c|}
\hline $\begin{array}{l}\text { Independent } \\
\text { Varibales }\end{array}$ & Items & Authors \\
\hline
\end{tabular}

15. In general, the top managers of my firm have a strong proclivity for high-risk projects (with chances of very high returns);

16. In general, the top managers of my firm believe that owning to the nature of the environment, bold,

Risk Taking wide-ranging acts are necessary to achieve the firm's objectives;

17. When confronted with decision-making situations involving uncertainty, my firm typically adopts a bold, aggressive posture in order to maximize the probability of exploiting potential opportunities.
(Beliaeva, Shirokova, Wales and Gafforova, 2018) Based on the Likert scale adapted from Covin and Slevin (1989) and Lumpkin and Dess (2001). Ranging from $1=$ "not at all" to 7 = "almost every day".
18. Cuts in financial resources (salaries, bonuses, resources for training and development);

19. Layoffs;

Working 20. Increased amount of work per person (workload);

Conditions 21. Negative attitudes from the side of employer/manager (yelling, excessive criticism, mobbing-physical and mental abuse, threatening); 22. Fear of losing your job.

23. The business's ability to recover from a major interruption is reliant on resources that originate from my personal network of social relationships;

Personal 24. I can rely on goodwill from my network to support recovery from a major incident; 25. Do you think that you have a large personal network?

Network
(Psychogios, Nyfoudi, Theodorakopoulos, Szamosi and Prouska, 2019)

Based on the Likert scale ranging from $1=$ "not at all" to 7 = "almost every day".

\section{References}

1. Dias, Á.L.; Silva, R.; Patuleia, M.; Estêvão, J.P.; González-Rodríguez, M.R. Selecting lifestyle entrepreneurship recovery strategies: A response to the COVID-19 pandemic. Tour. Hosp. Res. 2021, 1-7. [CrossRef]

2. Dias, Á.; Patuleia, M.; Silva, R.; Estêvão, J.; González-Rodríguez, M.R. Post-pandemic recovery strategies: Revitalizing lifestyle entrepreneurship. J. Policy Res. Tour. Leis. Events 2021, 1-7. [CrossRef]

3. Tomé, E.; Gromova, E.; Hatch, A. Did the Bubble Burst? The Portuguese Economy During COVID-19. Manag. Mark. Chall. Knowl. Soc. 2020, 15, 477-495. [CrossRef]

4. European Parliament. Pequenas e Médias Empresas. 2021. Available online: https://www.europarl.europa.eu/ftu/pdf/pt/FTU_ 2.4.2.pdf\#: \{\}:text=As $\% 20$ micro $\% 2 C \% 20$ pequenas $\% 20 \mathrm{e} \% 20 \mathrm{~m} \% \mathrm{C} 3 \%$ A 9 dias $\% 20$ empresas $\% 20 \% 28 \mathrm{PME} \% 29 \% 20$ constituem, areconstru $\%$ C3\%A7\%C3\%A30\%20e \%20o\%20refor\%C3\%A7o\%20da\%20resili\%C3\%AAncia\%20das\%20PME (accessed on 3 September 2021)

5. EY-Parthenon Portugal. A Crise Económica da COVID-19. Factos e Perspetivas, Desafios e Respostas (Issue 1). 2020. Available online: https:/ / assets.ey.com/content/dam/ey-sites/ey-com/pt_pt/topics/covid-19/ey-caderno-de-notas-a-crise-economicada-covid-19-v1-edicao.pdf (accessed on 7 September 2021).

6. Arenhardt, D.L.; Simonetto, E.D.O.; Rodrigues, G.O. Importance of Innovation for European SMEs: Perception of Experts. Dimens. Empresarial 2018, 16, 21-37. [CrossRef]

7. Turoń, K.; Kubik, A. Business Innovations in the New Mobility Market during the COVID-19 with the Possibility of Open Business Model Innovation. J. Open Innov. Technol. Mark. Complex. 2021, 7, 195. [CrossRef]

8. Aksoy, H. How do innovation culture, marketing innovation and product innovation affect the market performance of small and medium-sized enterprises (SMEs)? Technol. Soc. 2017, 51, 133-141. [CrossRef]

9. Adla, L.; Gallego-Roquelaure, V.; Calamel, L. Human resource management and innovation in SMEs. Pers. Rev. 2019, 49, 1519-1535. [CrossRef]

10. Giancotti, M.; Mauro, M.; Giancotti, M. Building and improving the resilience of enterprises in a time of crisis: From a systematic scoping review to a new conceptual framework. Econ. Aziend. Online 2020, 11, 307-339. [CrossRef]

11. Rajnoha, R.; Lorincova, S. Strategic Management of Business Performance Based on Innovations and Information Support in Specific Conditions of Slovakia. J. Compet. 2015, 7, 3-21. [CrossRef]

12. Antonioli, D.; Montresor, S. Innovation persistence in times of crisis: An analysis of Italian firms. Small Bus. Econ. 2021, 56, 1739-1764. [CrossRef] 
13. Dias, Á.; Silva, G.M.; Patuleia, M.; González-Rodríguez, M.R. Transforming local knowledge into lifestyle entrepreneur's innovativeness: Exploring the linear and quadratic relationships. Curr. Issues Tour. 2020, 24, 3222-3238. [CrossRef]

14. Tajeddini, K. Effect of customer orientation and entrepreneurial orientation on innovativeness: Evidence from the hotel industry in Switzerland. Tour. Manag. 2010, 31, 221-231. [CrossRef]

15. Campo, S.; Díaz, A.M.; Yagüe, M.J. Hotel innovation and performance in times of crisis. Int. J. Contemp. Hosp. Manag. 2014, 26, 1292-1311. [CrossRef]

16. Divisekera, S.; Nguyen, V.K. Determinants of innovation in tourism evidence from Australia. Tour. Manag. 2018, 67, 157-167. [CrossRef]

17. Al-Fadly, A. Impact of COVID-19 on SMEs and employment. Entrep. Sustain. Issues 2020, 8, 629-648. [CrossRef]

18. Kukanja, M.; Planinc, T.; Sikošek, M. Crisis Management Practices in Tourism SMEs During the Covid-19 Pandemic. Organizacija 2020, 53, 346-361. [CrossRef]

19. Povolná, L. Innovation Strategy in Small and Medium Sized Enterprises (SMEs) in the Context of Growth and Recession Indicators J. Open Innov. Technol. Mark. Complex. 2019, 5, 32. [CrossRef]

20. Beliaeva, T.; Shirokova, G.; Wales, W.; Gafforova, E. Benefiting from economic crisis? Strategic orientation effects, trade-offs, and configurations with resource availability on SME performance. Int. Entrep. Manag. J. 2018, 16, 165-194. [CrossRef]

21. Psychogios, A.; Nyfoudi, M.; Theodorakopoulos, N.; Szamosi, L.T.; Prouska, R. Many Hands Lighter Work? Deciphering the Relationship between Adverse Working Conditions and Organization Citizenship Behaviours in Small and Medium-sized Enterprises during a Severe Economic Crisis. Br. J. Manag. 2019, 30, 519-537. [CrossRef]

22. Herbane, B. Rethinking organizational resilience and strategic renewal in SMEs. Entrep. Reg. Dev. 2019, 31, 476-495. [CrossRef]

23. Dias, Á.L.; Manuel, E.C.; Dutschke, G.; Pereira, R.; Pereira, L. Economic crisis effects on SME dynamic capabilities. Int. J. Learn. Change 2021, 13, 63-80. [CrossRef]

24. Buffa, F.; Franch, M.; Rizio, D. Environmental management practices for sustainable business models in small and medium sized hotel enterprises. J. Clean. Prod. 2018, 194, 656-664. [CrossRef]

25. Mittal, S.; Khan, M.A.; Romero, D.; Wuest, T. A critical review of smart manufacturing \& Industry 4.0 maturity models: Implications for small and medium-sized enterprises (SMEs). J. Manuf. Syst. 2018, 49, 194-214. [CrossRef]

26. Thorgren, S.; Williams, T.A. Staying alive during an unfolding crisis: How SMEs ward off impending disaster. J. Bus. Ventur. Insights 2020, 14, e00187. [CrossRef]

27. Ayandibu, A.O.; Houghton, J. The role of Small and Medium Scale Enterprise in local economic development (LED). J. Bus. Retail. Manag. Res. 2017, 11, 133-139.

28. Muller, P.; Robin, N.; Jessie, W.; Schroder, J.; Braun, H.; Becker, L.S.; Farrenkopf, J.; Ruiz, F.A.; Caboz, S.; Ivanova, M.; et al. Annual Report on European SMEs 2018/2019-Research \& Development and Innovation by SMEs. 2019. Available online: https:/ / ec europa.eu/docsroom/documents/38365/attachments/2/translations/en/renditions/native (accessed on 9 September 2021).

29. Juergensen, J.; Guimón, J.; Narula, R. European SMEs amidst the COVID-19 crisis: Assessing impact and policy responses. J. Ind. Bus. Econ. 2020, 47, 499-510. [CrossRef]

30. Lu, Y.; Wu, J.; Peng, J.; Lu, L. The perceived impact of the Covid-19 epidemic: Evidence from a sample of 4807 SMEs in Sichuan Province, China. Environ. Hazards 2020, 19, 323-340. [CrossRef]

31. Secinaro, S.; Calandra, D.; Biancone, P.P. Reflection on Coronavirus Accounting Impact on Small and Medium Sized Enterprises (SMEs) in Europe. Int. J. Bus. Manag. 2020, 15, 48. [CrossRef]

32. Syriopoulos, K. The impact of covid-19 on entrepreneurship and smes. J. Int. Acad. Case Stud. 2020, $26,5822$.

33. Domi, S.; Keco, R.; Capelleras, J.-L.; Mehmeti, G. Effects of innovativeness and innovation behavior on tourism SMEs performance: The case of Albania. Econ. Sociol. 2019, 12, 67-85. [CrossRef]

34. Luthans, F.; Avey, J.B.; Avolio, B.J.; Peterson, S.J. The development and resulting performance impact of positive psychological capital. Hum. Resour. Dev. Q. 2010, 21, 41-67. [CrossRef]

35. Tarba, S.Y.; Cooper, S.C.L.; Ahammad, M.F.; Khan, Z.; Rao-Nicholson, R. Resilience in Organizations: An Editorial. Appl. Psychol. 2019, 68, 579-582. [CrossRef]

36. Mithani, M.A. Adaptation in the face of the new normal. Acad. Manag. Perspect. 2020, 34, 508-530. [CrossRef]

37. Linnenluecke, M.K. Resilience in Business and Management Research: A Review of Influential Publications and a Research Agenda. Int. J. Manag. Rev. 2017, 19, 4-30. [CrossRef]

38. Sharma, G.D.; Thomas, A.; Paul, J. Reviving tourism industry post-COVID-19: A resilience-based framework. Tour. Manag. Perspect. 2021, 37, 100786. [CrossRef]

39. Falahat, M.; Ramayah, T.; Soto-Acosta, P.; Lee, Y.-Y. SMEs internationalization: The role of product innovation, market intelligence, pricing and marketing communication capabilities as drivers of SMEs' international performance. Technol. Forecast. Soc. Chang. 2020, 152, 119908. [CrossRef]

40. Dias, Á.; Silva, G.M.; Patuleia, M.; González-Rodríguez, M.R. Developing sustainable business models: Local knowledge acquisition and tourism lifestyle entrepreneurship. J. Sustain. Tour. 2020, 1-20. [CrossRef]

41. Su, Z.; Xie, E.; Wang, D. Entrepreneurial Orientation, Managerial Networking, and New Venture Performance in China. J. Small Bus. Manag. 2015, 53, 228-248. [CrossRef]

42. Vaillant, Y.; Lafuente, E. Entrepreneurial experience and the innovativeness of serial entrepreneurs. Manag. Decis. 2019, 57, 2869-2889. [CrossRef] 
43. Martínez-Román, J.A.; Romero, I. Determinants of innovativeness in SMEs: Disentangling core innovation and technology adoption capabilities. Rev. Manag. Sci. 2017, 11, 543-569. [CrossRef]

44. Kumarasamy, D.; Singh, P. Access to Finance, Financial Development and Firm Ability to Export: Experience from Asia-Pacific Countries. Asian Econ. J. 2018, 32, 15-38. [CrossRef]

45. Paper, E. Fostering the use of Intangibles to strengthen SME access to finance. OECD SME Entrep. Papers 2019, 12, 81-97. [CrossRef]

46. Sibanda, K.; Hove-Sibanda, P.; Shava, H. The impact of SME access to finance and performance on exporting behaviour at firm level: A case of furniture manufacturing SMEs in Zimbabwe. Acta Commer. 2018, 18, 13. [CrossRef]

47. Carrillo-Hidalgo, I.; Pulido-Fernández, J.I. The Role of the World Bank in the Inclusive Financing of Tourism as an Instrument of Sustainable Development. Sustainability 2019, 12, 285. [CrossRef]

48. Serrasqueiro, Z.; Nunes, P.M. Determinants of Growth in Portuguese Small and Medium-Sized Hotels: Empirical Evidence Using Panel Data Models. Tour. Econ. 2016, 22, 375-396. [CrossRef]

49. Rupeika-Apoga, R.; Solovjova, I. Access to Finance for Latvian SMEs. Eur. Res. Stud. J. 2017, 20, 57-68. [CrossRef]

50. Rivera, J.P.R. Greater access to finance as driving factor for sustainable development among tourism-related SMEs in the Philippines: An empirical framework John Paolo R. Rivera 1. J. Asia Pac. Stud. 2019, 37, 37-45.

51. Adegboye, A.; Iweriebor, S. Does Access to Finance Enhance SME Innovation and Productivity in Nigeria? Evidence from the World Bank Enterprise Survey. Afr. Dev. Rev. 2018, 30, 449-461. [CrossRef]

52. Fowowe, B. Access to finance and firm performance: Evidence from African countries. Rev. Dev. Financ. 2017, 7, 6-17. [CrossRef]

53. Huang, A.; Jahromi, M.F. Resilience building in service firms during and post COVID-19. Serv. Ind. J. 2021, 41, 138-167. [CrossRef]

54. Hock-Doepgen, M.; Clauss, T.; Kraus, S.; Cheng, C.-F. Knowledge management capabilities and organizational risk-taking for business model innovation in SMEs. J. Bus. Res. 2021, 130, 683-697. [CrossRef]

55. Hudakova, M.; Masar, M.; Luskova, M.; Patak, M.R. The Dependence of Perceived Business Risks on the Size of SMEs. J. Compet. 2018, 10, 54-69. [CrossRef]

56. Tipu, S.A.A. Entrepreneurial risk taking: Themes from the literature and pointers for future research. Int. J. Organ. Anal. 2017, 25, 432-455. [CrossRef]

57. Nanda, R.; Rhodes-Kropf, M. Financing Risk and Innovation. Manag. Sci. 2017, 63, 901-918. [CrossRef]

58. Games, D.; Rendi, R.P. The effects of knowledge management and risk taking on SME financial performance in creative industries in an emerging market: The mediating effect of innovation outcomes. J. Glob. Entrep. Res. 2019, 9, 44. [CrossRef]

59. Pikkemaat, B. Innovation in Small and Medium-Sized Tourism Enterprises in Tyrol, Austria. Int. J. Entrep. Innov. 2008, 9, 187-197. [CrossRef]

60. Dias, Á.; Pereira, L.; da Costa, R.L. Organizational Capabilities as Antecedents of Entrepreneurship: A Basis for Business Practice and Policy Making. J. Afr. Bus. 2021, 1-18. [CrossRef]

61. Držajić, K.; Vega, F. Working Conditions as a Factor of Productivity in Smes. Radni Uslovi Kao Faktor Produktivnosti U Malim I Srednjim Preduzećima. EMC Rev. Časopis Ekon. Apeiron 2018, 8, 118-133. [CrossRef]

62. Mizla, M. Innovation Paradoxes and SMEs. 2013. Available online: https://bazekon.uek.krakow.pl/rekord/171447468 (accessed on 16 November 2021).

63. Darsø, L. Innovation Competency-An Essential Organizational Asset. In Employee-Driven Innovation; Palgrave Macmillan: London, UK, 2012; pp. 108-126.

64. Athota, V.S.; Malik, A. Managing Employee Well-Being and Resilience for Innovation: Evidence from Knowledge-Intensive Service Industries; Springer: Berlin/Heidelberg, Germany, 2019. [CrossRef]

65. Ojo, A.; Fawehinmi, O.; Yusliza, M. Examining the Predictors of Resilience and Work Engagement during the COVID-19 Pandemic. Sustainability 2021, 13, 2902. [CrossRef]

66. Ooms, W.; Werker, C.; Caniëls, M. Personal and social proximity empowering collaborations: The glue of knowledge networks. Ind. Innov. 2018, 25, 833-840. [CrossRef]

67. Udomkit, N.; Schreier, C. Tie the Ties: The Significance of the Binding Networks in SMEs' Internationalization Process. J. Asia Pac. Bus. 2017, 18, 1-17. [CrossRef]

68. Gronum, S.; Verreynne, M.-L.; Kastelle, T. The Role of Networks in Small and Medium-Sized Enterprise Innovation and Firm Performance. J. Small Bus. Manag. 2012, 50, 257-282. [CrossRef]

69. Ioanid, A.; Deselnicu, D.C.; Militaru, G. The impact of social networks on SMEs' innovation potential. Procedia Manuf. 2018, 22, 936-941. [CrossRef]

70. Lopes, J.; Oliveira, M.; Lopes, J.; Zaman, U. Networks, Innovation and Knowledge Transfer in Tourism Industry: An Empirical Study of SMEs in Portugal. Soc. Sci. 2021, 10, 159. [CrossRef]

71. Iborra, M.; Safón, V.; Dolz, C. What explains the resilience of SMEs? Ambidexterity capability and strategic consistency. Long Range Plan. 2019, 53, 101947. [CrossRef]

72. Sadri, A.M.; Ukkusuri, S.V.; Lee, S.; Clawson, R.; Aldrich, D.; Nelson, M.S.; Seipel, J.; Kelly, D. The role of social capital, personal networks, and emergency responders in post-disaster recovery and resilience: A study of rural communities in Indiana. Nat. Hazards 2018, 90, 1377-1406. [CrossRef]

73. Woiceshyn, J.; Daellenbach, U. Evaluating inductive vs deductive research in management studies. Qual. Res. Organ. Manag. Int. J. 2018, 13, 183-195. [CrossRef] 
74. Willey, J.Z.; Moon, Y.P.; Kulick, E.R.; Cheung, Y.K.; Wright, C.B.; Sacco, R.L.; Elkind, M.S. Physical Inactivity Predicts Slow Gait Speed in an Elderly Multi-Ethnic Cohort Study: The Northern Manhattan Study. Neuroepidemiology 2017, 49, 24-30. [CrossRef]

75. Creswell, J.W. Introduction to Mixed-Methods Research. In Research Methods in Public Administration and Nonprofit Management; Routledge: London, UK, 2017; pp. 415-425.

76. Patrick, P.; Osadebe, U. Evaluation of Undergraduate Students' Performance in Test and Measurement Achievement Test with Samples from Probabilistic and Non- Probabilistic Sampling Procedures. Asian J. Assess. Teach. Learn. 2017, 7, 26-31. [CrossRef]

77. Peterson, R.A.; Merunka, D.R. Convenience samples of college students and research reproducibility. J. Bus. Res. 2014, 67, 1035-1041. [CrossRef]

78. Codó, E. Interviews and Questionnaires. In The Blackwell Guide to Research Methods in Bilingualism and Multilingualism; Wiley: Hoboken, NJ, USA, 2008; pp. 158-176.

79. Dester, A. Exploring the effects that an on-site psychologist(s) has on students: A qualitative study on private tertiary institution students using in-depth interviews. IIE 2020, 148, 148-162.

80. Ringle, C.M.; Da Silva, D.; Bido, D.D.S. Structural equation modeling with the Smart PLS Abstract. Braz. J. Mark. 2014, 13, 56-73. [CrossRef]

81. Hair, J.F., Jr.; Sarstedt, M.; Ringle, C.M.; Gudergan, S.P. Advanced Issues in Partial Least Squares Structural Equation Modeling; SAGE Publications: Thousand Oaks, CA, USA, 2017.

82. Bagozzi, R.P.; Yi, Y. On the evaluation of structural equation models. J. Acad. Mark. Sci. 1988, 16, 74-94. [CrossRef]

83. Fornell, C.; Larcker, D.F. Evaluating structural equation models with unobservable variables and measurement error. J. Mark. Res. 1981, 18, 39-50. [CrossRef]

84. Falk, R.F.; Miller, N.B. A Primer for Soft Modeling; University of Akron Press: Akron, OH, USA, 1992.

85. Hjalager, A.M. 100 Innovations That Transformed Tourism. J. Travel Res. 2015, 54, 3-21. [CrossRef]

86. Baldwin, R.; Mauro, B.W.; Boone, L.; Haugh, D.; Pain, N.; Salins, V.; McKibbbin, W.; Fernando, R.; Arezki, R.; Nguyen, H.; et al. The economic effects of a pandemic. In Economics in the Time of COVID-19; CEPR Press: London, UK, 2020.

87. Halunko, V.; Chyzhmar, I.; Kurkova, K. Modern mechanism of strengthening innovative activity of transport enterprises. Balt. J. Econ. Stud. 2018, 4, 33-41. [CrossRef]

88. Turon, K.; Kubik, A.; Chen, F. Electric Shared Mobility Services during the Pandemic: Modeling Aspects of Transportation. Energies 2021, 14, 2622. [CrossRef]

89. Pereira, L.; Pinto, M.; Costa, R.L.D.; Dias, Á.; Gonçalves, R. The New SWOT for a Sustainable World. J. Open Innov. Technol. Mark. Complex. 2021, 7, 18. [CrossRef] 